\title{
QUANTIFICATION OF RESIDUAL CLOVE OIL, BENZOCAINE AND TRICAINE IN FISH FILLETS USING SPE AND UPLC-DAD
}

Robson A. Pereira, Adelir A. Saczk*, Daniel Okamura, Maria das Graças Cardoso, Leandro S. Costa, Wilder D. Santiago, Thallis M. Souza, Rafael M. Felix de Lima, Priscila V. e Rosa

*Department of Chemistry, Federal University of Lavras (UFLA), Lavras - MG, Brazil; Phone: +55 3538291876 ; Fax: +553538291812 .

E-mail: adelir@dqi.ufla.br

\begin{abstract}
Residual quantification of the anesthetics clove oil (CO) - isoeugenol (ISO), eugenol (EUG) and methyleugenol (MET) -, benzocaine (BZN) and tricaine (MS-222) was made in fillets of two fish species: Nile tilapia (Oreochromis niloticus) and a catfish hybrid, cachadia (Pseudoplatystoma reticulatum x Leiarius marmoratus). Samples $(n=4)$ of each fish were evaluated after submitted to anesthesia in five dosages defined based on the induction time of each species after depuration times $(0 \mathrm{~h}, 12 \mathrm{~h}, 24 \mathrm{~h}$ and $48 \mathrm{~h}$ ). Different methodologies of sample preparation were tested and selected according to the better recovery. The quantification of anesthetics was performed by UPLC-DAD. The variance of residual means among anesthetics, dosages and fish species was compared. After anesthesia (Oh) both species, tilapia and cachadia, presented residual anesthetics. Fishes depurated during $12 \mathrm{~h}, 24 \mathrm{~h}$ and $48 \mathrm{~h}$ did not present detectable values, it means, values were below the limits of detection. BZN presented the highest mean residual concentration for tilapia and cachadia $(p=0.01)$, while MS-222 presented the lowest residual amounts in tilapias and EUG in cachadias, what may be related to the metabolism and carcass composition of each fish species. There were no significant differences among the five dosages, except the lowest MS-222 concentration in tilapias that resulted in higher residual concentrations because low dosages increase the induction time and consequently the permanence of the fish in anesthesia. Ultimately, mean values of residues in cachadia were higher than in tilapia, and MS-222 and EUG presented the lowest residual values for tilapia and cachadia, respectively.
\end{abstract}

\section{Indexing terms/Keywords}

Anesthetics; Residual analysis; Tilapia fillet; Cachadia fillet; UPLC-DAD.

\section{Academic Discipline And Sub-Disciplines}

Analytical Chemistry

\section{SUBJECT CLASSIFICATION}

Procedures in sample extraction by SPE; analysis in UPLC-DAD.

\section{TYPE (METHOD/APPROACH)}

Experimental Analysis

\section{Council for Innovative Research}

Peer Review Research Publishing System

Journal: Journal of Advances in Chemistry

Vol. 10, No. 5

editorjaconline@gmail.com 


\section{Introduction}

On aquaculture the management, transport, marking, application of hormones and vaccines cause intense stress on animals, and in this context anesthetic or analgesic compounds have been applied trying to ease the negative effect of such practices (Mettam et al., 2011; Sneddon, 2009; Ross et al., 2008).

Nowadays the most used anesthetics on aquaculture are MS-222, BZN, CO or formulations containing its active ingredient: ISO, menthol, quinaldine and metomidate (CCAC, 2011; FDA, 2011; Kiessling et al., 2009). Such compounds may persist on the animal organism even after being metabolized, and then it is necessary to define the adequate depuration period for each species and anesthetics applied, as well as the conditions for application, like concentration, time of permanence in anesthesia and recovery (Mettam et al., 2011; Sneddon, 2009).

The anesthetic residual period depends on factors like temperature, salinity, chemical composition of water, fat content, among others (Burka et al., 1997). Such factors may contribute differently with fishes of temperate and tropical regions, for example, once these last are submitted to higher temperatures, what explains their faster metabolism. Other important aspect to be considered is the physiology of each species since there are more than 30000 fish species (Zahl et al., 2012).

Fishes with scales like Nile tilapia andcatfishes like cachadia, both studied in this work, may absorb and excrete anesthetic compounds differently due to their different body composition and metabolism. Thus it is necessary to evaluate these factors in order to define the depuration time of such compounds on the organism of fishes submitted to anesthesia.

Countries like United States of America, Canada, Norway and United Kingdom regulated the MS-222 use for some fish species and already have commercial products. In these countries, fishes destined to the human consumptionthat have been anesthetized with MS-222 need to pass through a depuration period of 21 days before being liberated for consumption. BZN has the same regulation than MS-222 in Norway (Zahl et al., 2012; Carter et al., 2011).

South Korea, New Zealand, Australia, Costa Rica and Chile have already regulated the use of anesthetics containing the active principle ISO. However in these countries the depuration period is not necessary provided that parameters indicated by producers are respected (Zahl et al., 2012; Tuckey et al., 2012).

The depuration period may be defined through the quantification of anesthetic residues and their metabolites after exposition of fishes to anesthesia (Stehly et al., 2000; Stehly et al., 1995). All these results require methodologies that involve procedures of sample preparation like homogenization, extraction and purification for the definition of residual period, besides evaluating the capacity of anesthetics depuration by fishes (Meinertz et al., 2009; Meinertz et al., 2006; Meinertz et al., 1999).

Sample preparation may represent until $75 \%$ of the time spent in an analysis and it consists of an important step for the development of analytical methods. The combination of extraction procedures with purification and preconcentration like solid-phase extraction (SPE) and liquid-liquid extraction are necessary due to the complexity of the involved matrix (Baniceru et al., 2011).

This work aimed to define methodologies of sample preparation and residual quantification of BZN, MS-222 and $\mathrm{CO}$ in fillets of two species of tropical fishes, Nile tilapia (Oreochromis niloticus) and cachadia (Pseudoplatystoma reticulatum $\mathrm{x}$ Leiarius marmoratus), submitted to anesthesia in different dosages and depuration times using methodologies for extraction and quantification via UPLC-DAD.

\section{Material and Methods}

\section{Reagents}

The standards of ISO 98\% (2-methoxy-4-propenilfenol), MET 99\% (4-allyl-1,2-dimethoxybenzene), BZN $\geq 99 \%$ (Ethyl 4-aminobenzoate) and MS-222 98\% (3-aminobenzoate methanesulfonate acetate) were obtained from SigmaAldrich and EUG PESTANAL ${ }^{\circledR}$ (2-methoxy-4-(2-propenilfenol)) from Fluka. Methanol and acetonitrile HPLC grade, acetic acid ACS $\geq 99.7 \%$ grade, monohydrate citric acid $\geq 99.5 \%$, dibasic sodium phosphate $\geq 98.5 \%$ obtained from Sigma-Aldrich. Water type 1 (resistance > 18.2 M ) was obtained from a system of purification Sinergy® Milli-Q (Millipore).

\section{Experimental design}

Two different analytical methodologies were performed in order to evaluate three anesthetics on fish species. For the samples composition a factorial model with 30 treatments $(2 \times 3 \times 5)$ was adopted. The factorial consisted in the interaction of anesthesia of the two studiedspecies with three anesthetics (CO, BZN and MS-222) used in five dosages (Table 1). Each treatment was applied on four repetitions $(n=4)$, which were evaluated in four different depuration periods (0 h, $12 \mathrm{~h}, 24 \mathrm{~h}$ and 48h). 
Table 1. Dosages $\left(\mathrm{mg} \mathrm{L}^{-1}\right)$ of anesthetics used on fishes

\begin{tabular}{ccccccc}
\hline \multirow{2}{*}{ Dosages } & \multicolumn{3}{c}{ Tilapia } & \multicolumn{3}{c}{ Cachadia } \\
\cline { 2 - 7 } & CO & BZN & MS-222 & CO & BZN & MS-222 \\
\hline$[1]$ & 70 & 60 & 140 & 30 & 60 & 90 \\
{$[2]$} & 100 & 100 & 170 & 60 & 110 & 110 \\
{$[3]$} & 130 & 140 & 200 & 90 & 160 & 130 \\
{$[4]$} & 160 & 180 & 230 & 120 & 210 & 150 \\
{$[5]$} & 190 & 220 & 260 & 150 & 260 & 170 \\
\hline
\end{tabular}

CO: clove oil;BZN: benzocaine;MS-222: tricaine.

\section{Samples}

The samples were obtained by slaughtering the fish through a section of the spinal cord after being stunned on ice. All experiments were submitted to the Ethics Committee on Animals Usage (CEUA-UFLA) and approved under protocol 025/2013. Composed of fillets of two fish species, Nile tilapia (Oreochromis niloticus) with mean weight of $456.9 \pm$ $113.1 \mathrm{~g}$ and cachadia (Pseudoplatystoma reticulatum $\times$ Leiarius marmoratus) with mean weight of $345.6 \pm 80.98 \mathrm{~g}$. Fishes were submitted to five dosages of the anesthetics CO, BZN and MS-222 (Table 1) following procedures described by Okamura et al. (2010) in which dosages and time of permanence in anesthesia were optimized according to the ideal time of induction and recovery. Four depuration periods were adopted ( $0 \mathrm{~h}, 12 \mathrm{~h}, 24 \mathrm{~h}$ and $48 \mathrm{~h})$, before the fish slaughter and filleting. Fillets were frozen $\left(-20^{\circ} \mathrm{C}\right)$ and kept this way until the sample preparation.

\section{Extraction}

For the evaluation of analytes three procedures of homogenization were used after fillets defrosting using grinder, dry ice and maceration besides two extractive solutions, acetonitrile (100\%) and solution 50:50 (v/v) methanol:bufferMclllvaine $\mathrm{pH} 4.4$ (11.823 g of citric acid monohydrate and $16.4312 \mathrm{~g}$ of sodium phosphate dibasic dihydrate in $1 \mathrm{~L}$ of water type 1$)$.

On the extraction of CO, BZN and MS-222 analytes, the methodologies proposed by Kildea et al. (2004), Meinertz et al. (2009), Scherpenisse and Bergwerff (2007) and Meinertz et al. (2006, 1999) were evaluated. For extracting samples containing $\mathrm{CO}$, the Meinertz et al. $(2006,1999)$ procedure was modified: $5 \mathrm{~g}$ of macerated fillets were put in tubes of $50 \mathrm{~mL}$ and $5 \mathrm{~mL}$ of extractive solution were added. It was stirred during $5 \mathrm{~min}$ in a Vortex Mixer (Vixar $\left.{ }^{\circledR}\right)$ and the extract was centrifuged at $3400 \mathrm{rpm}$ during $5 \mathrm{~min}$. This procedure was repeated three times. Aliquots were grouped, concentrated by evaporation until half of the volume and diluted with water at $25 \mathrm{~mL}$ in order to perform the SPE procedure.

For BZN and MS-222 the Scherpenisse and Bergwerff (2007) method was modified: $5 \mathrm{~g}$ of fillet were stirred mechanically (Quimis ${ }^{\circledR}-2501$ ) for 10 min using $5 \mathrm{~mL}$ of extractive solution and centrifuged at $340 \mathrm{rpm}$ during $5 \mathrm{~min}$. This procedure was repeated three times. Aliquots were grouped, concentrated by evaporation until half of the volume and diluted with water in order to perform the SPE procedure.

\section{Solid-phase extraction}

The SPE procedure was performed in Manifold Vac Elut 12 (Agilent ${ }^{\circledR}$ ) coupled with a vacuum pump (Prismatec) using SPE cartridges Discovery® DSC-18 (3 mL; $500 \mathrm{mg})$. Cartridges were previously conditioned with $6 \mathrm{~mL}$ of methanol for $\mathrm{CO}$ samples and with $3 \mathrm{~mL}$ of methanol followed by Mclllvaine buffer for samples containing BZN and MS222.

After conditioning, samples were submitted to extraction under a flow of two drops per second. Analytes were eluted from cartridges by adding $1 \mathrm{~mL}$ of acetic acid (1\%) followed by $1 \mathrm{~mL}$ of methanol. Aliquots $(2.5 \mathrm{~mL})$ were filtered in membrane PTFE (13 mm d; $0.45 \mu \mathrm{m}$; Millex, Millipore).

\section{Chromatographic analyses}

An UPLC system (Shimadzu) interface CBM-20A was used, which was equipped with two high pressure pumps (LC-DAD), an automatic injector with auto-sampler (SIL-10AF) and DAD (SPD-M2OA) configured in the range of 200-700 nm. The flow was $0.8 \mathrm{~mL} \mathrm{~min}^{-1}$ and the mobile phase (isocratic mode) was composed by metanol:acetic acid $(60: 40 \mathrm{v} / \mathrm{v})$. Anesthetics separations were performed in column Ascentis ${ }^{\circledR} \mathrm{C} 18(250 \times 4.6 \mathrm{~mm} ; 5 \mu \mathrm{m}$, Supelco $)$, and precolumn Ascentis ${ }^{\circledR} \mathrm{C} 18$ Supelguard ${ }^{\mathrm{TM}} \mathrm{C} 18(25 \times 4.6 \mathrm{~mm} ; 5 \mu \mathrm{m}) .20 \mu \mathrm{L}$ of standard solution and samples were injected in the system UPLC-DAD.

\section{Selectivity and linearity}

The selectivity of method was evaluated by means of the analysis of tilapia and cachadia samples lacking the analytes of interest. Matrices $(n=6)$ of both species without analytes were fortified with analytical standards in five concentrations $\left(0.0 ; 0.5 ; 1.0 ; 1.5\right.$ and 2.0 times the LD). ${ }^{[21]}$ 
The selected wave lengths for analysis were: BZN (280 nm), MS-222 (315 nm), ISO $261 \mathrm{~nm}$ and EUG and MET in 275 $\mathrm{nm}$. Analytical curve was prepared from dilutions of stock solution $\left(1 \mathrm{~g} \mathrm{~L}^{-1}\right)$ in methanol.

\section{Limits of Detection and Quantification}

Limits of detection (LD) and quantification (LQ) for each compound were obtained from parameters of analytical curve and the equations (1) and (2).

$\mathrm{LD}=3.3 \times(\mathrm{s} / \mathrm{S})$
$\mathrm{LQ}=10 \times(\mathrm{s} / \mathrm{S})$

in which $\mathrm{S}$ is the estimate of standard-deviation of the regression equation and $\mathrm{S}$ is the slope or angular coefficient of analytical curve (Snyder et al., 1997).

\section{Accuracy and recovery}

The method accuracy was determined by means of recovery tests in which random samples of analytes were fortified with five different concentrations $(0.0 ; 0.5 ; 1.0 ; 1.5$ and 2.0 times the LD) (PNCRB, 2009). Recovery was calculated according to the equation (3):

$R(\%)=(($ obtained response $) /($ expected response $)) * 100$

(3)

\section{Statistical analysis}

Residual means obtained on repetitions of each treatment were submitted to variance analysis through the software SISVAR (5.1 Build 72). Variables that presented significant differences were compared through SNK (StudentNewman-Keuls) test considering $\alpha=0.01$ (Ferreira, 2011).

\section{Results and discussion}

The methodologies of quantification proposed by Scherpenisse and Bergwerff (2007) and Meinertz et al. (2009; 2006) involves homogenization of fillets using a grinder and dry ice, respectively. Maceration resulted on a satisfactory performance in relation to the recovery of analyzed analytes (Table 2) on matrices applied to this work, besides it has decreased costs with reagents, equipment and time spent per analysis, since a total of 30 samples per day were processed comparing with 17 made by Meinertz et al. (1999).

Table 2. Analytical parameters for anesthetics quantification

\begin{tabular}{ccccccc}
\hline Anesthetics & $\begin{array}{c}\text { Linearity } \\
\left(\mathrm{mg} \mathrm{L}^{-1}\right)\end{array}$ & $\mathrm{R}$ & $\begin{array}{c}\mathrm{LD} \\
\left(\mu \mathrm{g} \mathrm{g}^{-1}\right)\end{array}$ & $\begin{array}{c}\mathrm{LQ} \\
\left(\mu \mathrm{g} \mathrm{g}^{-1}\right)\end{array}$ & \multicolumn{2}{c}{ Rec.(\%) } \\
\hline BZN & $0.013-13.21$ & 0.9999 & 0.06 & 0.1819 & 94.02 & 90.66 \\
MS-222 & $0.013-13.21$ & 0.9999 & 0.0446 & 0.1352 & 95.58 & 92.91 \\
ISSO & $0.013-0.33$ & 0.9998 & 0.0146 & 0.0441 & 94.68 & 96.72 \\
EUG & $0.013-13.33$ & 0.9999 & 0.0414 & 0.1255 & 90.84 & 92.86 \\
MET & $0.014-14.26$ & 0.9998 & 0.1515 & 0.4590 & 85.61 & 83.46
\end{tabular}

BZN: benzocaine; MS-222 : tricaine; ISO: isoeugenol; EUG: eugenol; MET: methyleugenol.

R: correlation coefficient;LD: limit of detection; LQ: limit of quantification;Rec.: recovery; C: cachadia; T: tilapia.

Between the two extractive solutions evaluated, acetonitrile (100\%) was efficient on removing $\mathrm{CO}$ and the solution 50:50(v/v) methanol: Mclllvaine buffer pH 44 for BZN and MS-222.Such results are in accordance with the tested methodologies and are related to the chemical properties of analytes and their interaction with extractive solutions during the analysis.

Methodologies proposed by Kildea et al. (2004) and Meinertz et al. (1999) recovered poorly the studied compounds and therefore they were not used for quantifying such compounds on the matrices. Thereby, samples containing BZN and MS-222 were submitted to the methodology of Scherpenisse and Bergwerff (2007) adapted, and on samples with CO the procedures adapted from Meinertz et al. $(2009 ; 2006)$ was used.

SPE was adapted to the conditions and volume of extracts, it represented an important step for the quantification and contributed for the method selectivity. 
Figure 1 presents the chromatogram of method selectivity when quantifying residues of BZN, MS-222 and CO in fishes. Standards of EUG, ISO and MET were injected to analyze CO.

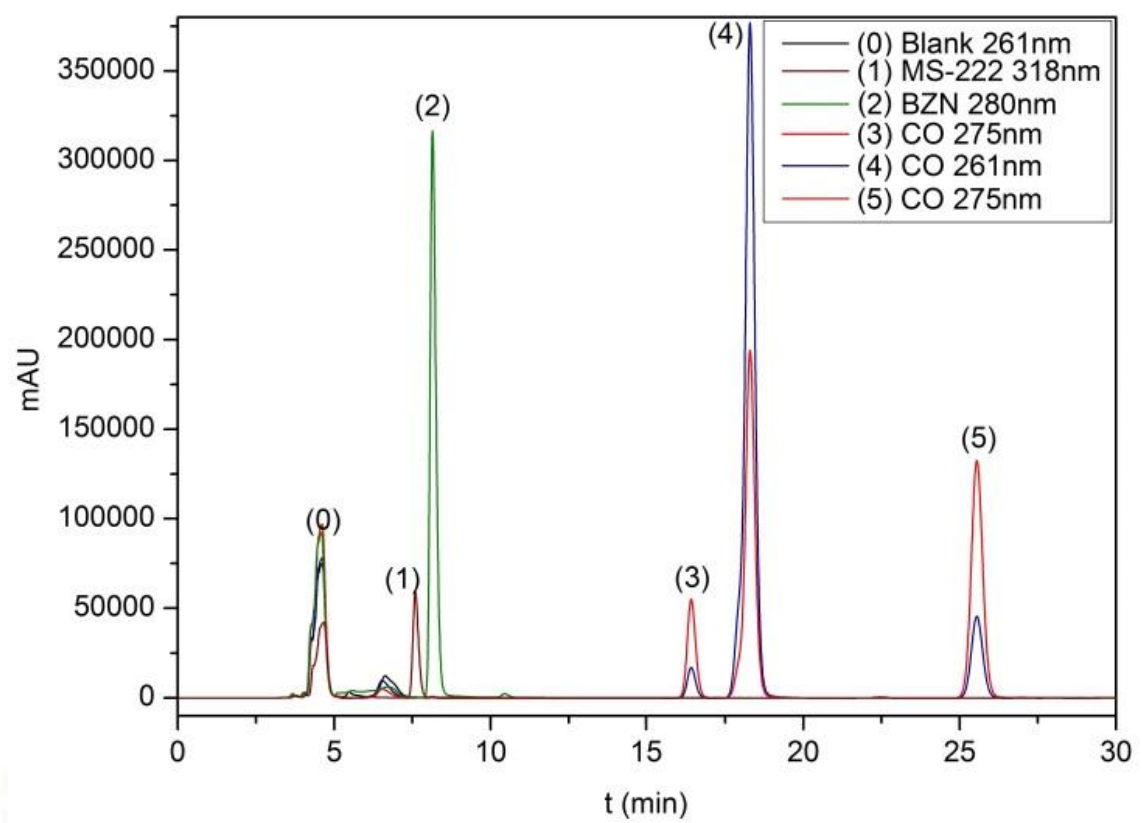

Figure 1. Chromatogram of fish sample without the studied compounds (0) and fortified with standard solution of tricaine (MS-222) with retention time $\left(R_{t}\right)=7.53 \mathrm{~min}(1)$, benzocaine (BZN) $R_{t}=8.12 \mathrm{~min}(2)$, eugenol (EUG) $R_{t}=16.34 \mathrm{~min}$ (3), isoeugenol (ISO) $R_{t}=18.22$ min (4), methyleugenol(MET) $R_{t}=25.55 \min (5)$.

The method selectivity for anesthetics was similar for both fish species. CO was analyzed in two wave lengths in which each compound presented higher absorbance, because the residual quantification requires the selection of wave lengths with higher responses in order to ensure the correct quantification. Thereby, $275 \mathrm{~nm}$ was selected for EUG and MET and $261 \mathrm{~nm}$ for ISO.This method selectivity allowed the simultaneous determination of all used anesthetics and consequently provided the possibility to apply such technique in residual analyses of matrices submitted to anesthesia compounded by more than one active principle. Nowadays the combination of different anesthetics and analgesics has been used in order to decrease toxic effects, therefore studies regarding the residual period of such anesthetics are needed (Mettam et al., 2011; Huang et al., 2010; Zahl et at., 2009).

The analytical curve was plotted from the dilution of a stock solution $\left(1 \mathrm{~g} \mathrm{~L}^{-1}\right)$ in methanol and analytical parameters obtained by the proposed method are listed on Table 2.

The linearity corresponded to the applied range of concentration $\left(0.013-14.26 \mathrm{mg} \mathrm{L}^{-1}\right) . \mathrm{BZN}$ recovery $(94.02 \%$ for cachadia and $90.66 \%$ for tilapia) was similar to what Meinertz et al. (1999) found for BZN in rainbow trout (Oncorhynchus mykiss). For cachadia and tilapia the MS-222 recovery was approximately $20 \%$ higher than values related by Scherpenisse and Bergwerff (2007) also analyzing MS-222 in tilapias. For ISO, 94.68\% was recovered in cachadias and $96.72 \%$ in tilapias, values next to those found by Meinertz and Schreier $(2009 ; 2006)(88.8-95.8 \%)$ for rainbow trout. Moreover, LD and LQ in the present work are inferior to Meinertz and Schreier (2009) results, thus allowing that residual analyses may be performed in lower concentrations of this compound.

Anesthetics quantification was performed comparing the retention time of compounds on the fortified samples with values obtained on samples of anesthetized fishes. Mean residual concentrations found on fillets of cachadia and tilapia are listed on Table 3. 
Table 3.Values obtained through residual analysis of fishes (in $\mu \mathrm{g} \mathrm{g}^{-1}$ )

\begin{tabular}{|c|c|c|c|c|c|c|c|c|c|c|c|}
\hline \multirow{2}{*}{$\begin{array}{c}\text { Depuration } \\
\text { period }\end{array}$} & \multirow{2}{*}{ Dosage } & \multicolumn{5}{|c|}{ Nile tilápia } & \multicolumn{5}{|c|}{ Cachadia } \\
\hline & & BZN & MS-222 & ISO & EUG & MET & BZN & MS-222 & ISO & EUG & MET \\
\hline \multirow{7}{*}{$0 \mathrm{~h}$} & [1] & 1.9979 & $0.9884 a$ & ND & 0.5512 & ND & 3.5107 & 2.9155 & ND & 1.2298 & ND \\
\hline & [2] & 1.4102 & $0.1985 b$ & $<\mathrm{LQ}$ & 0.4310 & ND & 2.2712 & 1.6383 & ND & 0.7210 & ND \\
\hline & [3] & 2.1334 & $0.2479 b$ & ND & 0.5194 & ND & 1.9682 & 2.7520 & $<\mathrm{LQ}$ & 0.8032 & ND \\
\hline & [4] & 1.0179 & $0.2328 b$ & ND & 0.5121 & ND & 2.3067 & 1.7324 & $<L Q$ & 1.4743 & ND \\
\hline & [5] & 0.7425 & $0.3201 \mathrm{~b}$ & ND & 0.5543 & ND & 2.9486 & 1.8295 & ND & 0.7075 & ND \\
\hline & Mean & $1.4604^{\mathrm{a}}$ & $0.3975 \mathrm{~B}$ & - & $0.5136 \mathrm{~B}$ & - & $2.6011 \mathrm{~A}$ & $2.173 \mathrm{~A}$ & - & $0.987 \mathrm{~B}$ & - \\
\hline & $V^{1}$ & \multicolumn{5}{|c|}{46.84} & \multicolumn{5}{|c|}{24.85} \\
\hline \multirow{7}{*}{$12 \mathrm{~h}$} & [1] & $<L Q$ & ND & ND & ND & ND & 0,2568 & ND & ND & ND & ND \\
\hline & [2] & ND & ND & ND & ND & ND & ND & ND & ND & ND & ND \\
\hline & [3] & ND & ND & ND & ND & ND & ND & ND & ND & ND & ND \\
\hline & [4] & ND & ND & ND & ND & ND & ND & ND & ND & ND & ND \\
\hline & [5] & ND & ND & ND & ND & ND & ND & ND & ND & ND & ND \\
\hline & Mean & - & - & - & - & - & - & - & - & - & - \\
\hline & $\mathrm{VC}^{1}$ & & & & & & & & - & & \\
\hline
\end{tabular}

BZN: benzocaine; MS-222: tricaine; ISO: isoeugenol; EUG: eugenol; MET: methyeugenol.

Means followed by different uppercase on the rows and lowercase on columns differ according to the Student-NewmanKeuls test $(P<0.01) .<L Q=$ values detected below the limit of quantification.

ND: the sample did not present detectable values (<LD).

${ }^{1}$ Variation coefficient of ANOVA (Analysis of Variance)

On samples submitted to treatments with CO it was possible to determine EUG in both fish species, while ISO only was detected. This is due to the mean composition of CO ( 85\% EUG), thus EUG suppresses other constituents in lower proportions, which did not attain quantifiable and detectable values

After anesthesia $(0 \mathrm{~h})$ the mean of residues of the five BZN dosages was $1,46 \mu \mathrm{g} \mathrm{g}^{-1}$ on tilapias, value significantly superior to EUG $\left(0.514 \mu \mathrm{g} \mathrm{g}^{-1}\right)$ and to MS-222 $\left(0.397 \mu \mathrm{g} \mathrm{g} \mathrm{g}^{-1}\right)$. Different results were observed for cachadias, in which BZN $\left(2.6 \mu \mathrm{g} \mathrm{g}^{-1}\right)$ and MS-222 $\left(2.17 \mathrm{\mu g} \mathrm{g}^{-1}\right)$ presented residual means superior to EUG (0.987). BZN provided higher residual values right after anesthesia both for tilapia and cachadia. This may be explained by the rapid absorption and low solubility in water (approximately 250 times lower than MS-222), thus justifying its prohibition by Food and Drug Association (FDA) that allows using the MS-222 isomer (FDA, 2011; Burka et al.,.., 1997). CO (EUG) did not present differences in relation to MS-222 in tilapias, while in cachadia values were inferior to MS-222 and BZN.

When comparing residual means among the five dosages applied, there was no significant difference for most of the treatments, except MS-222 in tilapias for which the lowest dosage resulted in higher residual concentration. This is associated to the time that the fish was exposed to the anesthetics, once when lower dosages are used more time is required until the fish becomes anesthetized, what increases the time of exposition and consequently the absorption of anesthetics by the fish.

It is important to highlight that, contrarily to other studies involving residual analysis fishes evaluated in the present work kept less than 3 minutes immerse in anesthetics bath (considered the ideal time for anesthesia) (Meinertz et al., 2009; Meinertz et al., 2006; Kildeal et al., 2004). Dosages were defined in a manner that the time necessary for inducing anesthesia respected parameters of ideal anesthetics (Ross et al., 2008; Okamura et al., 2010; Keene et al., 1998; Vera et al., 2010).

When comparing mean values of residues between species, overall cachadia retained higher concentrations than tilapia, presenting higher concentrations of MS-222 on the fillets, while tilapias retained more BZN. This is probably associated to differences on the species biology, tilapias present scales and cachadia has leather skin, furthermore they have different food habits, metabolism and fillet compositions, what may have hampered the residue elimination.

After $12 \mathrm{~h}$ no more quantifiable values were obtained, except for the dosage [1] of BZN in cachadia. This concentration may have presented residual mean above LQ due to the longer time of induction, thus increasing the time of fish permanence in contact with the anesthetic. 
Samples related to periods of depuration did not present detectable values from $24 \mathrm{~h}$ on and this is the period recommended by Stehly et al. (2000) for BZN in rainbow trout (Oncorhynchus mykiss). Kildea et al. (2004) also did not observe detectable levels of $\mathrm{CO}$ in silver perch (Bidyanus bidyanus) after $48 \mathrm{~h}$. Tuckey and Forgan (2012) observed that residues of ISO in Australasian snapper (Pagrusauratus) change from $22.15 \mathrm{\mu g} \mathrm{g}^{-1}$ immediately after slaughtering to 1.3 $\mu \mathrm{g} \mathrm{g}^{-1}$ after seven hours of depuration, what suggests a possible total depuration after 24h Tuckey and Forgan (2012) and Guénette et al. (2007) determined the half-life time of CO (EUG) in rainbow trout at 12,14 h. However, all these studies were performed after 15 or $30 \mathrm{~min}$ of exposition to anesthetics, without considering stages of induction and recovery recommended for an ideal anesthetic: $3 \mathrm{~min}$ of induction and $5 \mathrm{~min}$ for recovering (Ross et al., 2008; Okamura et el., 2010; Keene et al., 1998; Vera et al, 2010).

Brazilian laws still do not regulate the depuration time required by fishes anesthetized on aquiculture. However producers and researchers need to attempt in relation to the use of international parameters without considering specific demands of the animal. This evidences the importance of determining the depuration times required by fishes submitted to ideal anesthesia, thus allowing defining an operational protocol that ensures safety for the fish farmer, the fish and finally for the consumer.

\section{Conclusion}

Methodologies proposed in the present work were efficient on quantifying residues of the anesthetics CO, BZN and MS-222 in Nile tilapia and cachadia, with BZN presenting the highest mean residual value for tilapia and CO with the lowest mean value for cachadia. Between the species, cachadia (in which BZN and MS-222 values were higher than MS222) accumulated more residual concentrations than tilapia. Nile tilapia accumulated residues of BZN on fillets, even after $12 \mathrm{~h}$ of depuration, as well as cachadia. There was no difference among dosages, except MS-222 for tilapias. Low dosages of anesthetics increases time of induction and consequently the time of fish permanence immerse on the anesthetics, thus contributing with higher residual concentrations on fillets.

\section{Aknowledgments}

Authors thank Ministério da Pesca e Aquicultura (MPA), Conselho Nacional de Desenvolvimento Científico e Tecnológico (CNPq), Fundação de Amparo à Pesquisa do Estado de Minas Gerais (FAPEMIG) and Coordenação de Aperfeiçoamento de Pessoal de Nível Superior (CAPES) for finantial support; Laboratório de Nutrição de Peixes - DZO/UFLA for providing samples, and Laboratório de Análise de Qualidade de Aguardentes - DQI/UFLA for technical support during analyses.

\section{References}

1. Baniceru, M.; Manda, C.V.; Popescu, S.M. Chromatographic analysis of local anesthetics in biological samples. J.Pharmaceut. Biomed. Anal. 2011, 54, 1-12.

2. Burka, J.F.; Hammell, K.L.; Horsberg, T.E.; Johnson, G.R.; Rainnie, D.J.; Speare, D.J. Drugs in salmonid aquaculture--a review. J.Vet. Pharmacol. Ther. 1997, 20, 333-49.

3. Carter, K.M.; Woodley, C.M.; Brown, R.S. A review of tricaine methanesulfonate for anesthesia of fish. Rev. Fish Biol. and Fisher. 2011, 21, 51-59.

4. CCAC. Canadian Council on Animal Care, 2011. Guidelines on: the care and use of fish in research, teaching and testing. URL (http://www.ccac.ca/Documents/Standards/Guidelines/Fish.pdf) (acessed Jun 23, 2013).

5. FDA. U.S. Food and Drug Administration. Fish and Fishery Products Hazards and Controls Guidance Fourth Edition- $\quad$ APRIL 2011.2 URL (http://www.fda.gov/downloads/Food/GuidanceComplianceRegulatorylnformation/GuidanceDocuments/Seafood/ UCM251970.pdf) (acessed Jun 23, 2013).

6. Ferreira, D.F. Sisvar: A Computer Statistical Analysis System. Ciênc. Agrotec. 2011, 35, 1039-1042.

7. Guénette, S.A.; Uhland, F.C.; Hélie, P.; Beaudry, F.; Vachon, P. Pharmacokinetics of eugenol in rainbow trout (Oncorhynchus mykiss). Aquaculture. 2007, 266, 262-265.

8. Huang, W.-C.; Hsieh, Y.-S.; Chen, I.-H.; Wang, C.-H.; Chang, H.-W.; Yang, C.-C.; Ku, T.-H.; Yeh, S.-R.; Chuang, Y.-J. Combined Use of MS-222 ( Tricaine) and Isoflurane Extends Anesthesia Time and Minimizes Cardiac Rhythm Side Effects in Adult Zebrafish. Zebrafish. 2010, 7, 297-304.

9. Keene, J.L.; Noakes, D.L.G.; Moccia, R.D.; Soto, C.G. The efficacy of clove oil as an anaesthetic for rainbow trout, Oncorhynchus mykiss (Walbaum). Aquac. Res. 1998, 29, 89-101.

10. Kiessling, A.; Johansson, D.; Zahl, I.H.; Samuelsen, O.B. Pharmacokinetics, plasma cortisol and effectiveness of benzocaine, MS-222 and isoeugenol measured in individual dorsal aorta-cannulated Atlantic salmon (Salmo salar) following bath administration. Aquaculture. 2009, 286, 301-308.

11. Kildea, M.A.; Allan, G.L.; Kearney, R.E. Accumulation and clearance of the anaesthetics clove oil and AQUI-STM from the edible tissue of silver perch (Bidyanus bidyanus). Aquaculture. 2004, 232, 265-277. 
12. Mettam, J.J.; Oulton, L.J.; McCrohan, C.R.; Sneddon, L.U. The efficacy of three types of analgesic drugs in reducing pain in the rainbow trout Oncorhynchus mykiss, Appl. Anim. Behav. Sci. 2011, 13, 265-274.

13. Meinertz, J.R.; Schreier, T.M. Depletion of isoeugenol residues from the fillet tissue of AQUI-STM exposed rainbow trout (Oncorhynchus mykiss). Aquaculture. 2009, 296, 200-206.

14. Meinertz, J.R.; Greseth, S.L.; Schreier, T.M.; Bernardy, J.A.; Gingerich, W.H. Isoeugenol concentrations in rainbow trout (Oncorhynchus mykiss) skin-on fillet tissue after exposure to AQUI-STM at different temperatures, durations, and concentrations. Aquaculture. 2006, 254 347-354.

15. Meinertz, J.R.; Stehly, G.R.; Hubert, T.D.; Bernardy, J.A. Liquid chromatographic determination of benzocaine and $\mathrm{N}$-acetylbenzocaine in the edible fillet tissue from rainbow trout. J.Chromatogr. A. 1999, 855, 255-60.

16. Okamura, D.; Araújo, F.G.; Rosa, P. V.; Freitas, R.T.F.; Murgas, L.D.S.; Cesar, M.P. Effect of benzocaine concentration and fish size on anesthesia and recovery in Nile tilapia. Rev. Bras. Zootecn. 2010, 39, 971-976.

17. PNCRB, Plano Nacional de Controle de Resíduos Biológicos. Ministério da Agricultura, Pecuária e Abastecimento, Brasil; Diário Oficial da União de 22/07 2009, Seção 1, 7.

18. Ross, L.G.; Ross, B. The Nature of Anaesthesia, Sedation and Analgesia. In Anaesthetic and sedative Techniques for Aquatic Animals; 3 rd. ed. Wiley-Blackwell, Oxford, 2008, 222 p.

19. Scherpenisse, P.; Bergwerff, A.A. Determination of residues of tricaine in fish using liquid chromatography tandem mass spectrometry. Anal. Chim. Acta. 2007, 586, 407-10.

20. Sneddon, L.U. Pain perception in fish: indicators and endpoints. ILAR journal / National Research Council. Inst. Lab. Anim. Resources 2009, 50, 338-342.

21. Snyder, L.R.; Kirkland, J.J.; Glajch, J.L. Completing the Method: Validation and Transfer. In Practical HPLC method Development. 2 nd ed.; J. Wiley, New York, NY, 1997, 694-697.

22. Stehly, G.R.; Meinertz, J.R.; Gingerich, W.H. Effects of temperature on the elimination of benzocaine and acetylated benzocaine residues from the edible fillet of rainbow trout (Oncorhynchus mykiss). Food Addit.Contam. 2000, 17, 387-393.

23. Stehly, G.R.; Meinertz, J.R.; Gingerich, W.H. Effect of temperature on the pharmacokinetics of benzocaine in rainbow trout ( Oncorhynchus mykiss ) after bath exposures. J. Vet. Pharmacol. Ther. 1998, 21, 121-127.

24. Stehly, G.R.; Meinertz, J.R.; Gingerich, W.H.; Mazik, P.M.; Gaikowski, M.P. Effects of temperature on the loss of benzocaine and acetylated benzocaine residues from edible tissues of channel catfish lctalurus punctatus. Final FDA Report. Contract 224-92-7036. 1995, Study CAP-94-00078-01,.

25. Tuckey, N.P.L.; Forgan, L.G. A rapid and simple fluorometric method for quantifying isoeugenol in seawater and in plasma and white muscle from Australasian snapper (Pagrus auratus). Food Chem. 2012, 133, 1664-1670.

26. Vera, L.M.; Ros-Sánchez, G.; García-Mateos, G.; Sánchez-Vázquez, F.J. MS-222 toxicity in juvenile seabream correlates with diurnal activity, as measured by a novel video-tracking method. Aquaculture. 2010, 307, $29-34$.

27. Zahl, I.H.; Samuelsen, O.; Kiessling, A. Anaesthesia of farmed fish: implications for welfare. Fish Physiol.Biochem. 2012, 38, 201-18.

28. Zahl, I.H.; Kiessling, A.; Samuelsen, O.B.; Hansen, M.K. Anaesthesia of Atlantic cod (Gadus morhua) - Effect of pre-anaesthetic sedation, and importance of body weight, temperature and stress. Aquaculture. 2009, 295, 5259. 